\title{
Implementation of a Markov Chain Monte Carlo method to inorganic aerosol modeling of observations from the MCMA-2003 campaign - Part II: Model application to the CENICA, Pedregal and Santa Ana sites
}

\author{
F. M. San Martini ${ }^{1, *}$, E. J. Dunlea ${ }^{2}$, R. Volkamer ${ }^{1,{ }^{* *}}$, T. B. Onasch ${ }^{3}$, J. T. Jayne ${ }^{3}$, M. R. Canagaratna ${ }^{3}$, \\ D. R. Worsnop ${ }^{3}$, C. E. Kolb ${ }^{3}$, J. H. Shorter ${ }^{3}$, S. C. Herndon ${ }^{3}$, M. S. Zahniser ${ }^{3}$, D. Salcedo ${ }^{4}$, K. Dzepina ${ }^{2,6}$, \\ J. L. Jimenez ${ }^{2,6}$, J. M. Ortega ${ }^{1, * *}$, K. S. Johnson ${ }^{1}$, G. J. McRae ${ }^{5}$, L. T. Molina ${ }^{1,7}$, and M. J. Molina ${ }^{1, * *}$ \\ ${ }^{1}$ Department of Earth, Atmospheric, and Planetary Sciences, Massachusetts Institute of Technology, Cambridge, MA, USA \\ ${ }^{2}$ Cooperative Institute for Research in the Environmental Sciences (CIRES), Univ. of Colorado at Boulder, Boulder, CO, USA \\ ${ }^{3}$ Aerodyne Research Inc., Billerica, MA, USA \\ ${ }^{4}$ Centro de Investigaciones Químicas, Universidad Autónoma del Estado de Morelos, Cuernevaca, Morelos, México \\ ${ }^{5}$ Department of Chemical Engineering, Massachusetts Institute of Technology, Cambridge, MA, USA \\ ${ }^{6}$ Department of Chemistry and Biochemistry, University of Colorado-Boulder, Boulder, CO, USA \\ ${ }^{7}$ Molina Center on Energy and the Environment, La Jolla, CA, USA \\ * now at: the Board on Chemical Sciences and Technology, National Academies, Washington, D.C., USA \\ ** now at: University of California San Diego, La Jolla, CA, USA \\ **** now at: Sandia National Laboratory, Livermore, CA, USA
}

Received: 29 May 2006 - Published in Atmos. Chem. Phys. Discuss.: 10 July 2006

Revised: 16 October 2006 - Accepted: 24 October 2006 - Published: 30 October 2006

\begin{abstract}
A Markov Chain Monte Carlo model for integrating the observations of inorganic species with a thermodynamic equilibrium model was presented in Part I of this series. Using observations taken at three ground sites, i.e. a residential, industrial and rural site, during the MCMA-2003 campaign in Mexico City, the model is used to analyze the inorganic particle and ammonia data and to predict gas phase concentrations of nitric and hydrochloric acid. In general, the model is able to accurately predict the observed inorganic particle concentrations at all three sites. The agreement between the predicted and observed gas phase ammonia concentration is excellent. The $\mathrm{NO}_{\mathrm{z}}$ concentration calculated from the $\mathrm{NO}_{\mathrm{y}}, \mathrm{NO}$ and $\mathrm{NO}_{2}$ observations is of limited use in constraining the gas phase nitric acid concentration given the large uncertainties in this measure of nitric acid and additional reactive nitrogen species. Focusing on the acidic period of 9-11 April identified by Salcedo et al. (2006), the model accurately predicts the particle phase observations during this period with the exception of the nitrate predictions after 10:00 a.m. (Central Daylight Time, CDT) on 9 April, where the model underpredicts the obser-
\end{abstract}

Correspondence to: F. M. San Martini

(ico@alum.mit.edu) vations by, on average, 20\%. This period had a low planetary boundary layer, very high particle concentrations, and higher than expected nitrogen dioxide concentrations. For periods when the particle chloride observations are consistently above the detection limit, the model is able to both accurately predict the particle chloride mass concentrations and provide well-constrained $\mathrm{HCl}$ (g) concentrations. The availability of gas-phase ammonia observations helps constrain the predicted $\mathrm{HCl}(\mathrm{g})$ concentrations. When the particles are aqueous, the most likely concentrations of $\mathrm{HCl}(\mathrm{g})$ are in the sub-ppbv range. The most likely predicted concentration of $\mathrm{HCl}(\mathrm{g})$ was found to reach concentrations of order $10 \mathrm{ppbv}$ if the particles are dry. Finally, the atmospheric relevance of $\mathrm{HCl}(\mathrm{g})$ is discussed in terms of its indicator properties for the possible influence of chlorine-mediated photochemistry in Mexico City.

\section{Introduction}

The deterioration of air quality in urban centers throughout the world is fueled by population growth, especially in urban centers, and increased emissions with further modernization and industrialization. About $70 \%$ of the population

Published by Copernicus GmbH on behalf of the European Geosciences Union. 


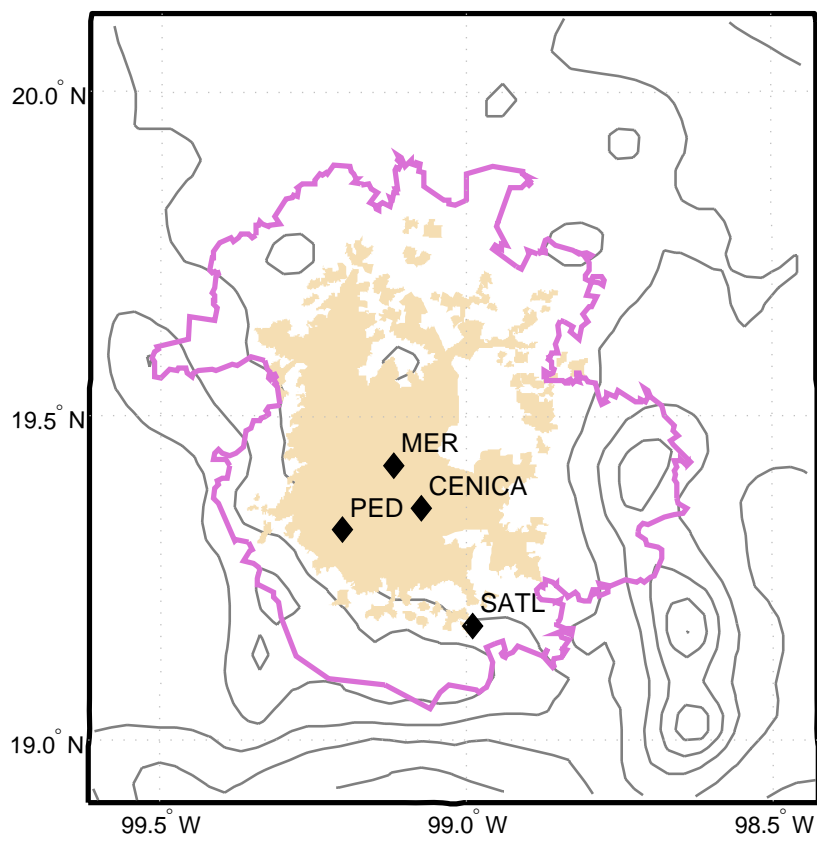

Fig. 1. Map of Mexico City basin showing the monitoring stations CENICA, Pedregal (PED) and Santa Ana (SATL). Also shown is the La Merced site (see San Martini et al., 2006). The contours are elevation contours, the pink line represents the Federal District and Estado de México limits, and the shaded area is the urban area of 1995.

of North America, Europe, and Latin America now live in cities (Molina and Molina, 2002). The 2003 Mexico City Metropolitan Area (MCMA) field campaign was designed to provide a scientific base for devising emission control strategies for the MCMA, as well as insights to air pollution problems in other megacities.

In Part I of this series, San Martini et al. (2006) have described an equilibrium inorganic aerosol model embedded in a Markov Chain Monte Carlo algorithm to produce a powerful tool to analyze aerosol data and predict gas phase concentrations where these are unavailable. The method directly incorporates measurement uncertainty, prior knowledge, and provides for a formal framework to combine measurements of different quality. Applying the model to gas and particle phase data taken at the La Merced site during the MCMA-2003 campaign, San Martini et al. (2006) showed that the model reproduced observations of particlephase ammonium, nitrate, and sulfate well. During periods where the particle chloride observations were consistently above the detection limit, the model reproduced the particle chloride observations well and predicted well-constrained gas-phase hydrochloric acid concentrations. In addition, the model was able to probabilistically discriminate between diverging observations of ammonia from two different instruments, a long-path and a point sample. The observations from the point sampler, which was co-located to the particle measurements, were shown to be more likely consistent with all the available observations and our knowledge of aerosol thermodynamics.

Previous work has shown that modeling aerosol behavior in Mexico City and, thus, design control strategies, is constrained primarily by a lack of observations of gas phase species (San Martini et al., 2005). In particular, the finding that reductions in ammonia concentrations are likely to be less effective than expected at reducing particle concentrations in Mexico City is constrained by observations at a single site, La Merced (San Martini et al., 2005). Therefore, an improved understanding of the temporal and spatial distribution of gas phase ammonia, nitric and hydrochloric acid concentrations is needed (San Martini et al., 2006, 2005). In this paper we use data from the MCMA-2003 campaign to expand the application of the model introduced in Part I to three very different measurement sites. We focus in particular on the acid period of 9-11 April 2003 identified by Salcedo (2006), and on the distribution of the inorganic particle and gas phase chloride.

\section{Measurement sites}

The Aerodyne Mobile Laboratory (AML) can be deployed in stationary sampling, mobile sampling and mapping, and vehicle chase mode (Kolb et al., 2004). Here we analyze data collected with the AML when it was deployed in stationary mode at three sites in different areas of Mexico City during MCMA-2003: the National Center for Environmental Research and Training (Centro Nacional de Investigación y Capacitatión Ambiental, abbreviated as CENICA), Pedregal, and Santa Ana sites. Figure 1 shows the locations of the CENICA, Pedregal, and Santa Ana sites in the Mexico City basin.

CENICA $\left(19.36^{\circ} \mathrm{N}, 99.07^{\circ} \mathrm{W}\right)$, the campaign supersite, is on the Iztapalapa campus of the Unversidad Autónoma Metropolitana. CENICA is approximately $10 \mathrm{~km}$ southeast of downtown Mexico City and near the conservation area Cerro de la Estrella. It is in a mixed commercial-residential area; to the west and south are mainly residential areas, and to the north and east are several factories and industries (Shirley et al., 2006). We also use data from an AMS deployed at the CENICA ground site, whose results have been summarized by Salcedo et al. (2006). The AML was deployed in stationary mode at the CENICA site at various times throughout the campaign.

Pedregal $\left(19.33^{\circ} \mathrm{N}, 99.20^{\circ} \mathrm{W}\right)$ is in the southwestern part of the MCMA in an affluent residential area with low vehicular traffic density. Prevailing daytime winds transport pollutants from the city center and industrial areas north of the city to this site. The AML was deployed in stationary mode at the Pedregal site from 05:32 p.m. (CDT) on 21 April to 11:14 p.m. (CDT) on 23 April 2003. 
The Santa Ana site $\left(19.177^{\circ} \mathrm{N}, 98.99^{\circ} \mathrm{W}\right)$ is located just outside the MCMA to the south. It is considered a 'boundary' site, as it is influenced by both clean background conditions and polluted outflow from the city at different times. It lies near the southeastern border of the Mexico City Federal District and on the western rim of a mountain pass that channels the southern outflow of air from the city. Santa Ana is a small, rural town, with agriculture as the predominant activity. The AML was deployed in stationary mode at the Santa Ana site from 09:25 p.m. (CDT) on 14 April to 09:42 p.m. (CDT) on 16 April 2003.

\section{Experimental}

Part I of this series (San Martini et al., 2006) and references therein describe the instruments onboard the AML, which include an aerosol mass spectrometer (AMS) and a quantum cascade tunable infrared laser differential absorption spectroscopy (TILDAS) instrument to measure gas phase ammonia.

The AML did not include an instrument to directly measure gas-phase $\mathrm{HNO}_{3}$. However, an estimate of the $\mathrm{HNO}_{3}$ concentration can be derived based on observations of NO, $\mathrm{NO}_{2}$, and total $\mathrm{NO}_{\mathrm{y}}$. As described in Part I, the AML included a commercial total $\mathrm{NO}_{\mathrm{y}}$ instrument, which measures both $\mathrm{NO}_{\mathrm{y}}$ and $\mathrm{NO}$, and a fast-response TILDAS $\mathrm{NO}_{2}$ instrument. From the total $\mathrm{NO}_{\mathrm{y}}$ and $\mathrm{NO}$ measurements, along with the TILDAS $\mathrm{NO}_{2}$ measurement, we calculate the non- $\mathrm{NO}_{\mathrm{x}}$ fraction of $\mathrm{NO}_{\mathrm{y}}$, referred to as $\mathrm{NO}_{\mathrm{z}}$ :

$\mathrm{NO}_{z}=\mathrm{NO}_{\mathrm{y}}-\mathrm{NO}-\mathrm{NO}_{2}$

$\mathrm{NO}_{\mathrm{z}}$ provides an (approximate) upper bound to the $\mathrm{HNO}_{3}$ concentration since $\mathrm{NO}_{\mathrm{Z}}$ may comprise $\mathrm{HNO}_{3}, \mathrm{RNO}_{3}, \mathrm{PAN}$, $\mathrm{HONO}, \mathrm{NO}_{3}, \mathrm{~N}_{2} \mathrm{O}_{5}$ and particulate $\mathrm{NO}_{3}^{-}$.

Temperature and relative humidity observations were obtained from the routine monitoring network in Mexico City (Red Automática de Monitoreo Atmosférico, RAMA), which operates sites at Pedregal and Santa Ana. The National Center for Environmental Research and Training provided temperature and relative humidity observations at CENICA. A synoptic characterization of the MCMA-2003 field campaign can be found in de Foy et al. (2005).

Part I demonstrated that co-located observations of particle species and gas-phase precursors are more likely to be consistent with all the available observations and our knowledge of aerosol thermodynamics. A combination of longpath rooftop observations and point observations showed a likelihood of additional influences on the long-path measurements from sources not collocated with the point measurements. Therefore this analysis did not use long-path gasphase ammonia observations collected by researchers from Argonne National Laboratory from the CENICA roof in the latter half of MCMA-2003. Similarly, but with one exception, we did not use observations from the second Aerodyne
AMS deployed on the CENICA roof. In order to investigate the acidic period identified by Salcedo et al. (2006), observations from the rooftop AMS were combined with the AML observations on 9 April when the AML AMS observations were not available. The speciation and mass concentrations reported by the two AMSs compared well, with some differences that are likely due to the different inlets used in both AMS instruments (Salcedo et al., 2006).

\section{Model description}

The model described in Part I (San Martini et al., 2006) was used here. In brief, a modified version of the inorganic aerosol model ISORROPIA (Nenes et al., 1998) was embedded in a Markov Chain Monte Carlo (MCMC) algorithm. ISORROPIA predicts the equilibrium partitioning of inorganic species between the gas and particle phase given inputs of temperature, relative humidity, and total pollutant concentrations. Based on the work of Mozurkewich (1993), the value of the equilibrium constant for the dissociation of solid ammonium nitrate in ISORROPIA was modified, as discussed in detail in Part I. Note that ISORROPIA includes inorganic species only; the effect of organic species on aerosol behavior is not included in the model. The possible impacts of this assumption are discussed in Sect. 6 .

The MCMC algorithm is a Bayesian method that allows for the inclusion of measurement uncertainty and inference of missing observations. Bayes' Theorem describes conditional probability:

$p(\theta \mid$ Data $)=\frac{p(\text { Data } \mid \theta) p(\theta)}{p \text { (Data })}$

where Data and $\theta$ are the observations and unknown variables, and $p(\theta \mid$ Data $), p($ Data $\mid \theta)$ and $p(\theta)$ are termed the posterior, likelihood and prior function, respectively. The term $p$ (Data) is a normalizing constant (equal to the probability of the observations).

The likelihood functions relating the observations and model predictions described in Part I are used here, with the exception that the only gas phase observations used here are from the TILDAS instrument on board the AML. Thus the measurement uncertainties for ammonia and $\mathrm{NO}_{\mathrm{z}}$ are $\pm 29 \%$ and $\pm 49 \%$ at the $95 \%$ confidence level, i.e., the likelihood function of the observations are described by normal distributions whose mean is the observation and whose standard deviation is proportional to the observation:

$$
\begin{aligned}
& p\left(\mathrm{NH}_{3}^{\mathrm{obs}} \mid \mathrm{NH}_{3}\right) \sim N\left(\mathrm{NH}_{3}^{\mathrm{obs}}, 0.15 \times \mathrm{NH}_{3}^{\mathrm{obs}}\right) \\
& p\left(\mathrm{NO}_{\mathrm{z}}^{\mathrm{obs}} \mid \mathrm{HNO}_{3}\right) \sim N\left(\mathrm{NO}_{\mathrm{z}}^{\mathrm{obs}}, 0.25 \times \mathrm{NO}_{\mathrm{z}}^{\mathrm{obs}}\right)
\end{aligned}
$$

where a normal probability density function with mean $\mu$ and standard deviation $\sigma$ is denoted as $N(\mu \mathrm{s} \sigma)$ and the superscript obs refers to observation. With the exception of 

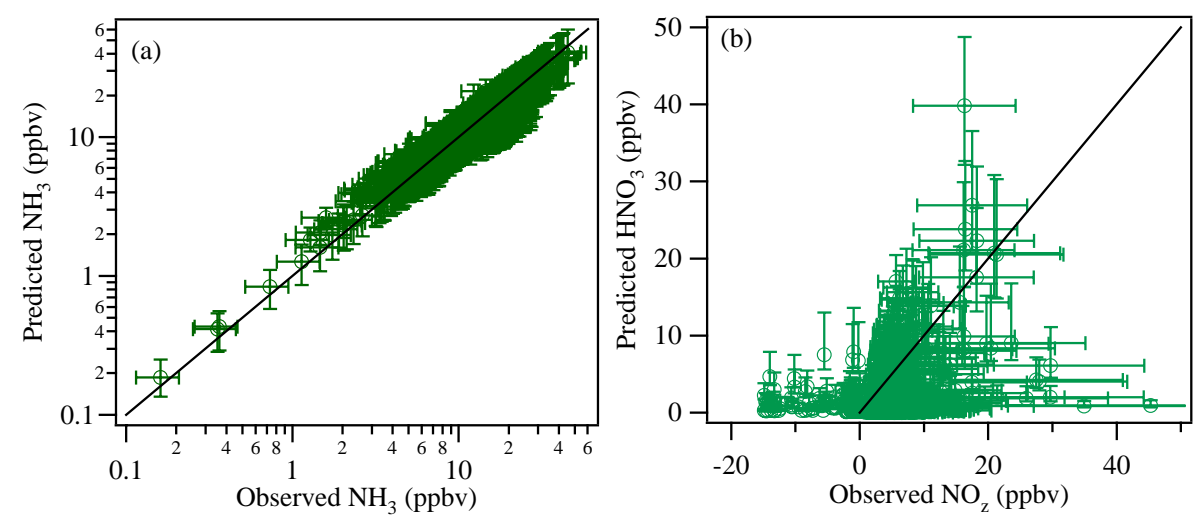

Fig. 2. Correlation plots for (a) ammonia and (b) $\mathrm{NO}_{\mathrm{z}}$ and nitric acid for CENICA. The error bars for the predictions represent the $95 \%$ confidence interval; the measurement uncertainty for ammonia and $\mathrm{NO}_{\mathrm{Z}}$ is $\pm 29 \%$ and $\pm 49 \%$.

9 April, the model is only run when both the particle and ammonia observations are available; modeling of 9 April is discussed in Sect. 5.1.

The AMS mass concentrations have a range of uncertainty of approximately $-30 \%$ and $+10 \%$ (Salcedo et al., 2006). Therefore, for the AMS observations above the detection limit, the likelihood function is a mixed Gaussian model (San Martini et al., 2006)

$$
\begin{aligned}
p\left(X^{\mathrm{obs}} \mid X\right)= & 0.7 \times N\left(X^{\mathrm{obs}}, 0.061 X^{\mathrm{obs}}\right) \\
& +0.3 \times N\left(0.85 X^{\mathrm{obs}}, 0.1275 X^{\mathrm{obs}}\right)
\end{aligned}
$$

where the superscript obs refers to observation and $X$ refers to the concentration of ammonium, nitrate, sulfate, or chloride. This asymmetric likelihood function is due to the uncertainty in particle collection efficiency.

The detection limits for ammonium, nitrate, and sulfate were $0.37,0.05,0.11 \mu \mathrm{g} / \mathrm{m}^{3}$, respectively. As described in San Martini et al. (2006), the detection limit used for chloride observations was $0.15 \mu \mathrm{g} / \mathrm{m}^{3}$; this is higher than the $0.05 \mu \mathrm{g} / \mathrm{m}^{3}$ detection limit reported by Salcedo et al. (2006) for the CENICA rooftop instrument. The higher detection limit for chloride was used because on average the chloride observations are between one and two orders of magnitude smaller (on a molar basis) than the other inorganic particle species, and due to the observed negative values. Moreover, given the uncertainty of the small chloride mass concentrations evidenced by the negative observations, the standard deviation for the chloride likelihood was doubled for observations between one and two times the detection limit, i.e., for chloride observations between 0.15 and $0.30 \mu \mathrm{g} / \mathrm{m}^{3}$ the likelihood function is:

$$
\begin{aligned}
p\left(\mathrm{Cl}^{\mathrm{obs}} \mid \mathrm{Cl}\right)= & 0.7 \times N\left(\mathrm{Cl}^{\mathrm{obs}}, 0.122 \mathrm{Cl}^{\mathrm{obs}}\right) \\
& +0.3 \times N\left(0.85 \mathrm{Cl}^{\mathrm{obs}}, 0.255 \mathrm{Cl}^{\mathrm{obs}}\right)
\end{aligned}
$$

The chloride observations and predictions are discussed further in the Results and Discussion section.
For all species, if an observation was below the detection limit, the likelihood function given by Eq. (5) was not used. Rather, for ammonium, nitrate, and sulfate, the uncertainty in the observation is assumed to be constant and equal to $\pm 49 \%$ of the detection limit (i.e., $\pm 0.18,0.025$, and $0.054 \mu \mathrm{g} / \mathrm{m}^{3}$ for ammonium, nitrate and sulfate, respectively, at the $95 \%$ confidence level). Chloride observations below the detection level were assumed to be negligible.

The prior $p(\theta)$ represents the uncertainty of $\theta$ before the data arrives: the prior thus contains all the information available about the unknown variables before the experiment begins. The same lognormal prior distributions described in Part I (San Martini et al., 2006) are used in this work:

$\mathrm{Na}_{\text {equiv }} \sim \log \mathrm{N}\left(6 \times 10^{-3}, 0.65\right)$

$\mathrm{NH}_{3} \sim \log \mathrm{N}(0.5,0.9)$

$\mathrm{HNO}_{3} \sim \log \mathrm{N}\left(1.5 \times 10^{-2}, 1.5\right)$

$\mathrm{HCl} \sim \log \mathrm{N}(0.02,1.4)$

where a lognormally distributed random variable $X$ with mode $X$ and standard deviation $\sigma$ is denoted as $X \sim \log \mathrm{N}(\widetilde{X}, \sigma)$.

\section{Results}

\subsection{CENICA}

The agreement between the predicted and observed ammonia concentrations for the periods when the AML was deployed in stationary mode at the CENICA site, shown in Fig. 2a, is excellent: of the 1140 points analyzed, the mode of 1,109 of the posterior ammonia distributions was within the measurement uncertainty (i.e., of the 1140 points analyzed, the predicted mode of $97 \%$ of these points was within the $29 \%$ measurement uncertainty, while the mode of the remaining 

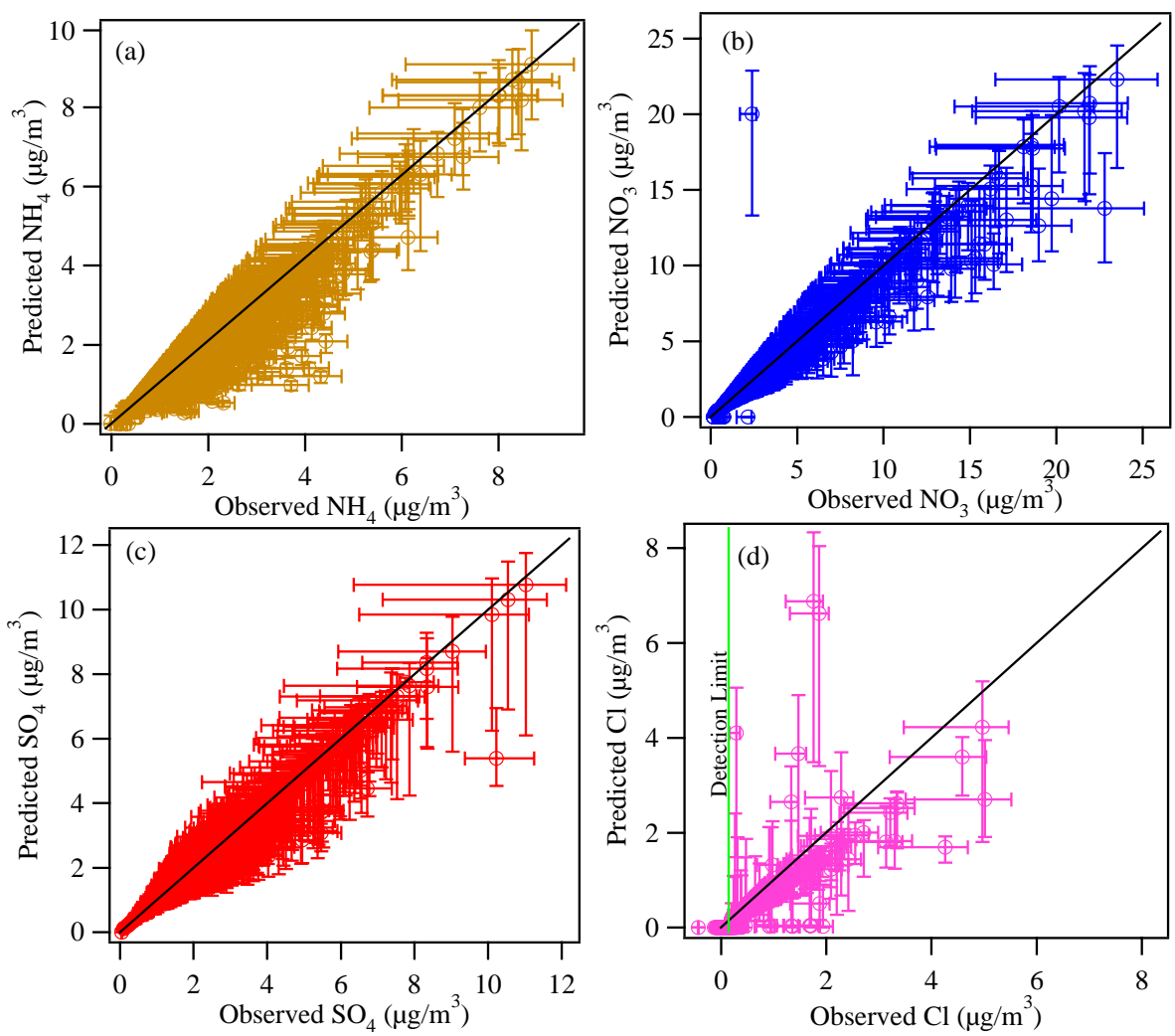

Fig. 3. Correlation plots for (a) ammonium, (b) nitrate, (c) sulphate, and (d) chloride for CENICA. The error bars for the predictions represent the $95 \%$ confidence interval; the measurement uncertainty is $+10 \%,-30 \%$. The detection limit for chloride is $0.15 \mu \mathrm{g} / \mathrm{m}^{3}$.

31 points was beyond $29 \%$ of the measurement). Of the 31 points where the mode of the distribution fell outside of the measurement uncertainty, the $95 \%$ confidence interval overlapped the measurement uncertainty in all but a single case. Figure $2 \mathrm{~b}$ compares the predicted nitric acid concentration with the calculated $\mathrm{NO}_{\mathrm{z}}$. In theory, the calculated $\mathrm{NO}_{\mathrm{z}}$ represents an upper limit for the nitric acid concentration. The limitation of $\mathrm{NO}_{\mathrm{z}}$ as a measure of nitric acid concentration can be seen both in the over-predictions and the significant negative $\mathrm{NO}_{z}$ values. Although considerable time and effort went into making the measurements used to calculate $\mathrm{NO}_{\mathrm{z}}$, it is clear that the uncertainties in this measure are large. Given the uncertainties, the utility of $\mathrm{NO}_{\mathrm{z}}$ as either a direct measure or upper limit for nitric acid for this dataset is limited.

Figure 3 compares the predicted and observed particle concentrations when the AML was parked at the CENICA site. In general, the predictions of ammonium, nitrate and sulfate are in good agreement with the observations, with only few predictions outside the measurement uncertainties. The agreement between the predicted and observed chloride concentrations is reasonable, though more variable, with both over- and under-predictions prevalent. The particle chloride observations and their predictions will be discussed more fully later. The predictions shown in Fig. 3 are assuming the aerosols are in thermodynamic equilibrium, i.e., in the stable (deliquescence) branch as opposed to the metastable (efflorescence) branch.

We now turn to the period 9-11 April highlighted by Salcedo et al. (2006). As defined by de Foy et al. (2005), 911 April corresponded to "Cold Surge" days, which were influenced by a cold air mass that reduced vertical mixing and boundary layer height. Very high particle concentrations were observed 9-11 April, with the highest particle concentrations of MCMA-2003 observed on 9 April. Despite partial cloudiness, intense photochemical activity combined with reduced dilution lead to very high concentration of both gas and particle phase pollutants on 9 April. The rooftop AMS observed peak concentrations a factor of $\sim 2$ higher than the average daily maximum nitrate concentration, and the peak nitrate concentration observed by the AML AMS was $\sim 10 \mu \mathrm{g} / \mathrm{m}^{3}$ higher than all other observed daily maximum nitrate concentrations. On 10 April, a large $\mathrm{SO}_{2}$ plume covered the northern half of the city, with a maximum concentration of $277 \mathrm{ppb}$ (de Foy et al., 2005).

Co-located gas and particle phase observations are available only intermittently on 9 April. The AML AMS observations are only available between 11:35 and 21:42 CDT; rooftop AMS observations are available from 00:00 and 19:00 CDT. Ammonia observations are available between 00:00 and 06:03 CDT, 11:07 and 13:40 CDT, and 18:52 and 


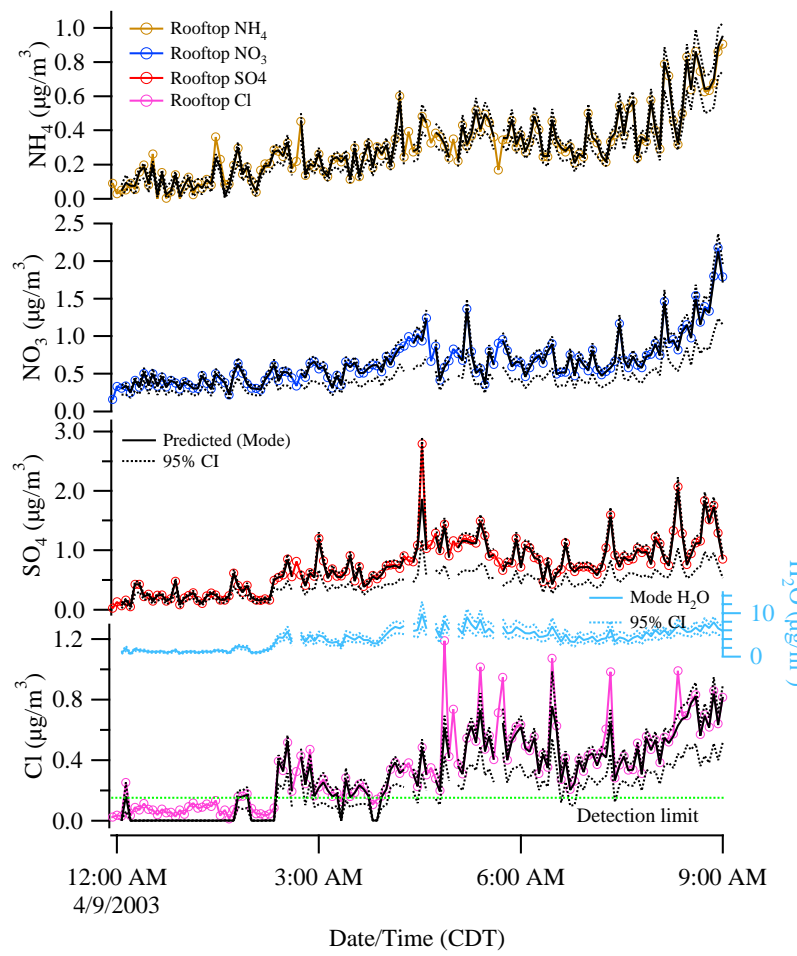

Fig. 4. Predicted (black) and observed (colored) concentrations of ammonium, nitrate, sulfate and chloride at CENICA from midnight to 09:00 a.m. (CDT) on 9 April. Note that the chloride observations are consistently above the $0.15 \mu \mathrm{g} / \mathrm{m}^{3}$ detection limit after 03:56 a.m. (CDT). The black dashed lines are the predicted $95 \%$ confidence intervals; the measurement uncertainty is $+10 \%,-30 \%$. The aerosols are predicted to be aqueous at equilibrium; also shown is the predicted aerosol water content (blue). For 9 April only the AMS observations include both rooftop and AML observations; the observations shown here are from the rooftop only (see text).

19:36 CDT. Given the interesting features observed by both AMS instruments, for 9 April only we have therefore combined the rooftop and AML AMS observations for the analysis. We use the rooftop observations between 00:00 and 11:35 CDT, and the AML observations between 11:35 and 19:36 CDT (see Figs. 4 and 5). Note that no ammonia observations are available between 06:03 and 11:07 CDT and 13:40 and 18:52 CDT. During these periods only the model was run with no ammonia observations: the only direct constraint on the ammonia concentration is provided by the prior probability distribution described in Part I. All other model runs described in this paper were constrained by ammonia observations.

An additional interesting feature of 9-11 April is the high relative humidity. In the late evening of 8 April, the relative humidity reached a peak of $96 \%$, at which point the particles will certainly be aqueous. The relative humidity remained high throughout the day except for several hours in the afternoon. Under stable equilibrium, and not consider-

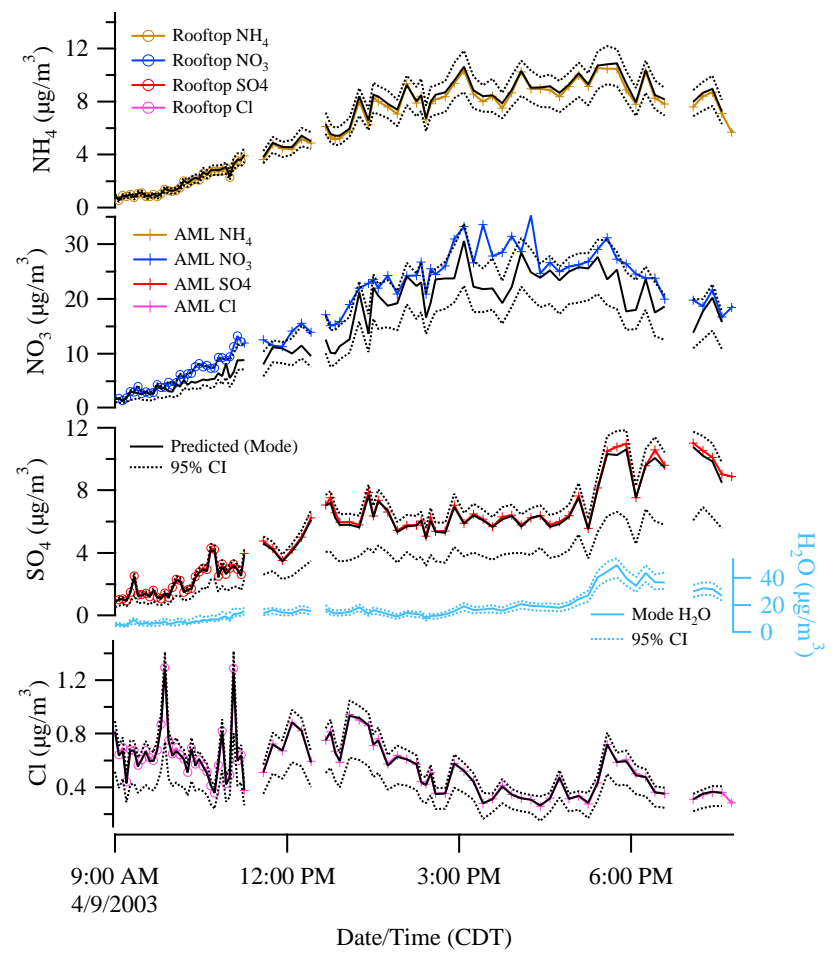

Fig. 5. Predicted (black) and observed (colored) concentrations of ammonium, nitrate, sulfate and chloride at CENICA from 09:00 to $19: 36$ (CDT) on 9 April. The chloride observations between 09:00 and 19:36 (CDT) are consistently above the $0.15 \mu \mathrm{g} / \mathrm{m}^{3} \mathrm{de}-$ tection limit (see text). Also shown is the predicted aerosol water content, where the aerosols are assumed to be in the metastable branch between noon and 05:00 p.m. (CDT) (see text); the average ionic strength during this period is $33 \mathrm{~mol} / \mathrm{kg}$. For 9 April only the AMS observations include both rooftop and AML observations; from 09:00 to 11:36 the observations are from the rooftop and from 11:35 to 19:36 from the AML (see text). The black dashed lines are the predicted $95 \%$ confidence intervals; the measurement uncertainty is $+10 \%,-30 \%$.

ing the relative humidity history, the particles are predicted to be dry between noon and 05:00 p.m. (CDT) on 9 April, and then become aqueous again after 05:00 p.m. as the relative humidity increases past the mutual deliquescence relative humidity. We investigated the sensitivity of assuming stable versus metastable equilibrium for this period only and found that differences between the predicted particle concentrations were negligible. Consistent with the results presented in Part I, the gas phase predictions between the stable and metastable case diverged. Since no gas phase observations are available during this period, and field observations indicate the prevalence of metastable particles (Rood et al., 1989), Fig. 5 therefore shows the predicted particle concentrations for 9 April for the case where the particles are assumed to be metastable. Note that during this period the relative humidity varied between 49 and 68\%; Rood et al. (1989) found that particles were metastable more than $50 \%$ of the time when the relative humidity was between $\sim 45$ and $75 \%$. 


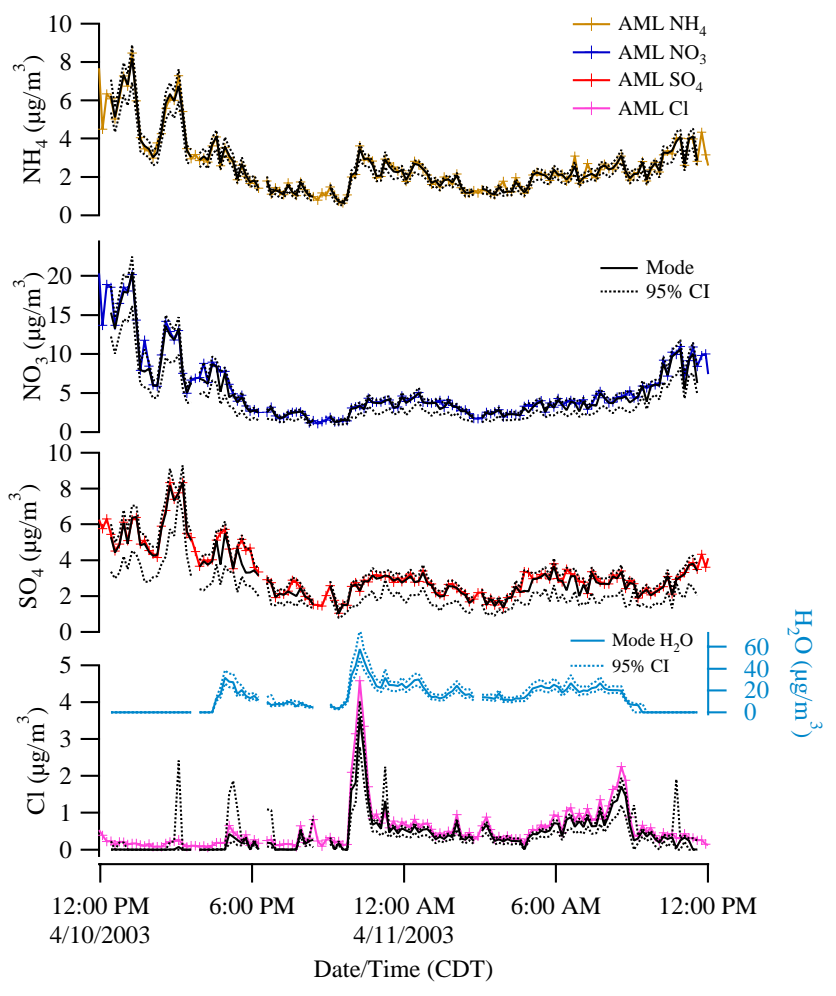

Fig. 6. Predicted (black) and observed (colored) concentrations of ammonium, nitrate, sulfate and chloride at CENICA from noon on 10 April to noon on 11 April. The aerosols are assumed to be stable; note that the aerosols are assumed to effloresce at 16:30 on 10 April and deliquesce at 09:30 on 11 April. The observations shown are from the AMS onboard the AML. The black dashed lines are the predicted $95 \%$ confidence intervals; the measurement uncertainty is $+10 \%,-30 \%$.

Due to a low planetary boundary layer during 9 April (de Foy et al., 2005; Volkamer et al., 2006), the particle concentrations observed on 9 April reveal two interesting features: (1) very high nitrate concentrations, and (2) that the chloride concentrations remain above the detection limit for most of the day. These will be discussed in turn. Figure $3 \mathrm{~b}$ shows generally good agreement between observed and predicted nitrate concentrations at CENICA, consistent with the findings at La Merced reported in Part I. Good agreement between nitrate predictions and observations is confirmed in Figs. 4 and 6, which show the observations and predictions of particle phase species for the early morning of 9 April and 10-11 April. Figure 5, however, shows that on 9 April after approximately 10:00 a.m. the model underpredicts the observed nitrate. Specifically, the mode of the predicted nitrate distribution is below the observation after 10:00 a.m., where the average underprediction is $20 \%$; the uncertainty bands of the observations and predictions, however, consistently overlap. In all cases, the 95\% confidence interval overlaps either the observation itself or the measurement uncertainty. With few exceptions, the mode of the predicted nitrate distribution

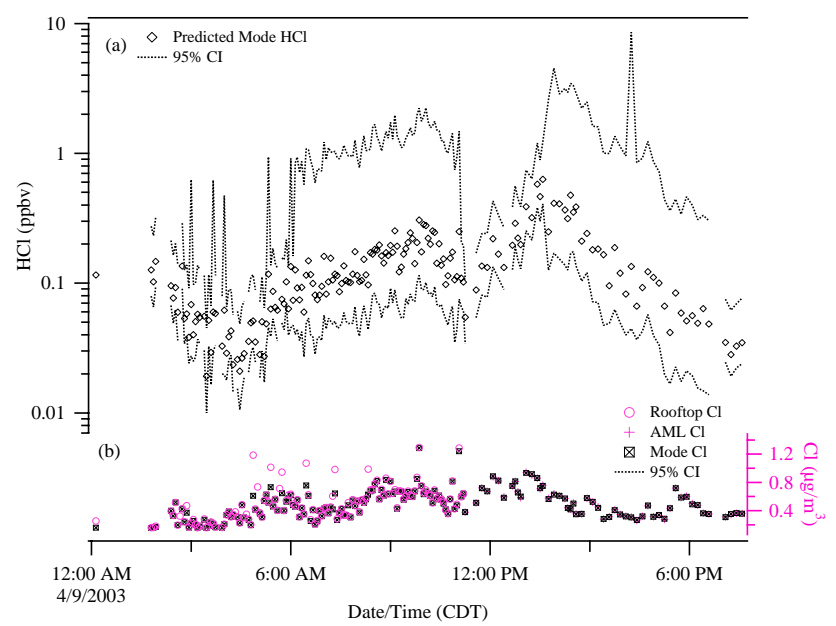

Fig. 7. (a) Posterior distribution of $\mathrm{HCl}$ (g) concentrations on 9 April at CENICA for the case where the aerosols are assumed to be metastable between noon and 05:00 p.m. (see text). The points represent the mode of the probability density function and the dashed lines are the $95 \%$ confidence intervals. The periods with a broad confidence interval are when no ammonia observations are available and the ammonia concentration is constrained by the prior (see text). (b) Predicted (mode) and observed aerosol chloride concentrations, where only the observations above the detection limit are shown. Between 09:00 and 11:36 the aerosol chloride observations are from the rooftop AMS and from 11:35 to 19:36 from the AMS onboard the AML (see text).

falls within the observation uncertainty (i.e., the mode of the predicted nitrate distribution is within $-30 \%$ of the observation). Possible explanations for the model nitrate underprediction are presented in the Discussion section.

The highest mass concentrations of chloride observed at CENICA during MCMA-2003 occur in the early morning (Salcedo et al., 2006). In general, chloride observations are below the detection limit during the rest of the day. In contrast, the chloride observations on 9 April consistently remain above the detection limit from 03:56 a.m. until the last available chloride observation of 9 April at 21:24 p.m. Figure 7 shows the observed and predicted particle chloride and the predicted $\mathrm{HCl}(\mathrm{g})$ concentration for the case where the aerosols are assumed to be metastable. The periods with narrow $\mathrm{HCl}(\mathrm{g})$ uncertainty bands correspond to the times where $\mathrm{NH}_{3}$ (g) observations are available, allowing the system to be well constrained. Conversely, periods with relatively large uncertainty bands (approximately a factor of 20) correspond to times when no direct $\mathrm{NH}_{3}(\mathrm{~g})$ observations are available and the only direct constraint on the gas phase concentrations are provided by the prior distributions described in Part I. Note that the mode of the $\mathrm{HCl}(\mathrm{g})$ concentration is continuous and does not "jump" between the periods with and without $\mathrm{NH}_{3}(\mathrm{~g})$ data, so that the main impact of the $\mathrm{NH}_{3}(\mathrm{~g})$ data is to greatly reduce the uncertainty in the predicted $\mathrm{HCl}(\mathrm{g})$. In Part I we showed that the predicted $\mathrm{HCl}$ (g) concentrations 


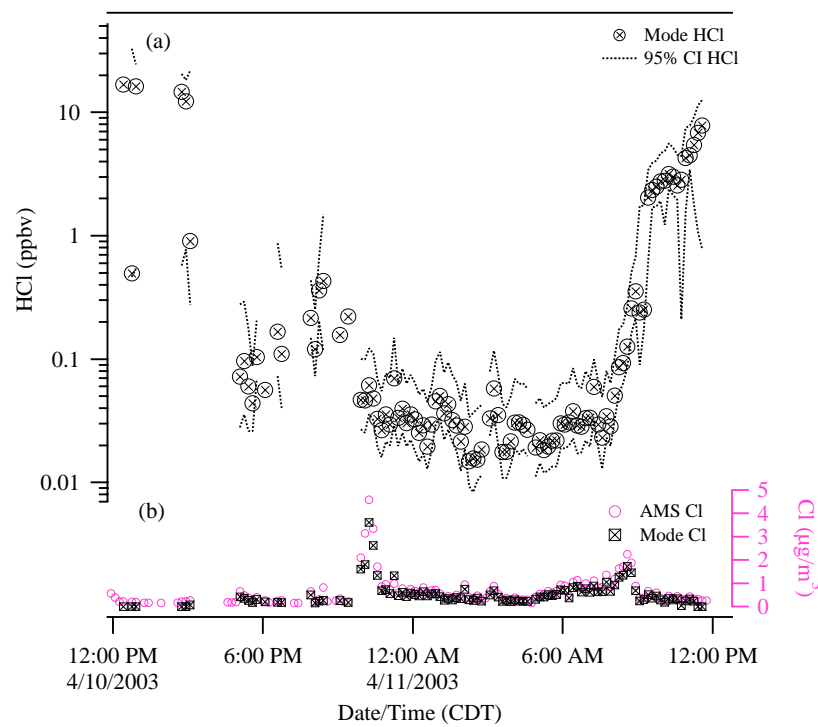

Fig. 8. (a) Posterior distribution of $\mathrm{HCl}$ (g) concentrations on 10-11 April at CENICA. The points represent the mode of the probability density function and the dashed lines are the $95 \%$ confidence intervals. Only points whose Markov Chain passed the convergence tests described in Part I are shown. (b) Predicted (mode) and observed aerosol chloride concentrations, where only the observations above the detection limit are shown. The aerosols are assumed to be stable; note that the aerosols are assumed to effloresce at 16:30 on 10 April and deliquesce at 09:30 on 11 April.

are well constrained when the observed chloride concentrations are consistently above the detection limit; this is confirmed in Fig. 7. This is also confirmed in Fig. 8, which shows the observed and predicted particle chloride and the predicted $\mathrm{HCl}(\mathrm{g})$ concentration for 10-11 April.

On 9 April, for the case where the aerosols are assumed to be metastable between noon and 05:00 p.m., the average and maximum most likely $\mathrm{HCl}(\mathrm{g})$ concentrations are 0.14 and 0.63 ppbv (see Fig. 7). Moreover, at the $95 \%$ confidence level, the concentration of $\mathrm{HCl}(\mathrm{g})$ remains above $0.01 \mathrm{ppbv}$ and below $2.4 \mathrm{ppbv}$ throughout the day except for two brief periods in the early afternoon (see Fig. 7). Note that the average predicted ionic strength for 9 April when the particles are assumed to remain aqueous throughout the day is $13.6 \mathrm{~mol} / \mathrm{kg}$. The average ionic strength between noon and 05:00 p.m. is $33 \mathrm{~mol} / \mathrm{kg}$. The predicted concentration of $\mathrm{HCl}$ $(\mathrm{g})$ is higher between noon and 05:00 p.m. if the particles are assumed to be dry. Between noon and 05:00 p.m. the predicted average and maximum most likely $\mathrm{HCl}(\mathrm{g})$ concentrations for the case where the particles are assumed to be dry (i.e., in the deliquescence branch) are 0.96 and 2.5 ppbv.

For 10-11 April, the $\mathrm{HCl}$ (g) concentrations are generally well constrained and predicted to be sub-ppbv (see Fig. 8). After 09:30 a.m. on 11 April the particles are predicted to deliquesce and the predicted $\mathrm{HCl}$ concentration increases to 2 ppbv, eventually reaching 8 ppbv at 11:35 a.m.

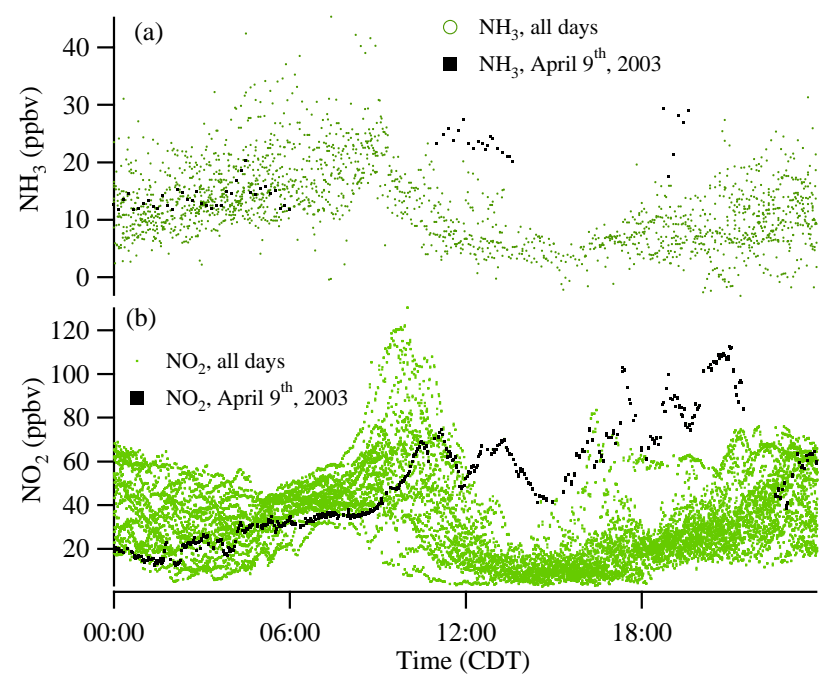

Fig. 9. (a) Observations of ammonia at CENICA from the TILDAS instrument onboard the AML by the time of day for all days (green) and for 9 April 2003 (black). (b) Concentration of $\mathrm{NO}_{2}$ measured by open-path DOAS by the time of day for all days (light green) and for 9 April 2003 (black).

A comparison of the $\mathrm{HCl}(\mathrm{g})$ concentrations predicted at CENICA with those predicted at La Merced (San Martini et al., 2006) is instructive. At La Merced, during periods where the particle chloride observations are consistently above the detection limit, the $\mathrm{HCl}(\mathrm{g})$ concentrations are well constrained, with concentrations ranging from sub-ppbv up to $\sim 10 \mathrm{ppbv}$. These predictions are very similar to those on 1011 April at CENICA (see Fig. 8). In contrast, on 9 April the most likely concentration of $\mathrm{HCl}(\mathrm{g})$ at CENICA is predicted to remain below $1 \mathrm{ppbv}$ throughout the day. This is in marked difference to the $\mathrm{HCl}(\mathrm{g})$ predictions at La Merced. For those brief periods at La Merced where the afternoon chloride concentration was above the $0.15 \mu \mathrm{g} / \mathrm{m}^{3}$ detection limit, the model was in general unable to reproduce these observations despite searching in very high $\mathrm{HCl}$ (g) concentration probability space (up to $\sim 100 \mathrm{ppbv}$ ) (San Martini et al., 2006). This difference is likely due to the higher than average ammonia concentrations on 9 April at CENICA, as well as cooler temperatures and higher relative humidity.

The importance of the low boundary layer on pollutant concentrations of 9 April highlighted by Volkamer et al. (2006) can be seen in Fig. 9. Figure 9a shows all the CENICA ammonia measurements from the TILDAS instrument onboard the AML by the time of day for all days (green) and for 9 April 2003 (black). Similarly, Fig. 9b shows the concentration of $\mathrm{NO}_{2}$ measured by open-path Differential Optical Absorption Spectroscopy (DOAS) (Volkamer et al., 2005) by the time of day for all days (light green) and for 9 April 2003 (black). The concentration of both ammonia and $\mathrm{NO}_{2}$ remain significantly higher in the afternoon of 9 April than on other days. The latter points to a significantly higher 

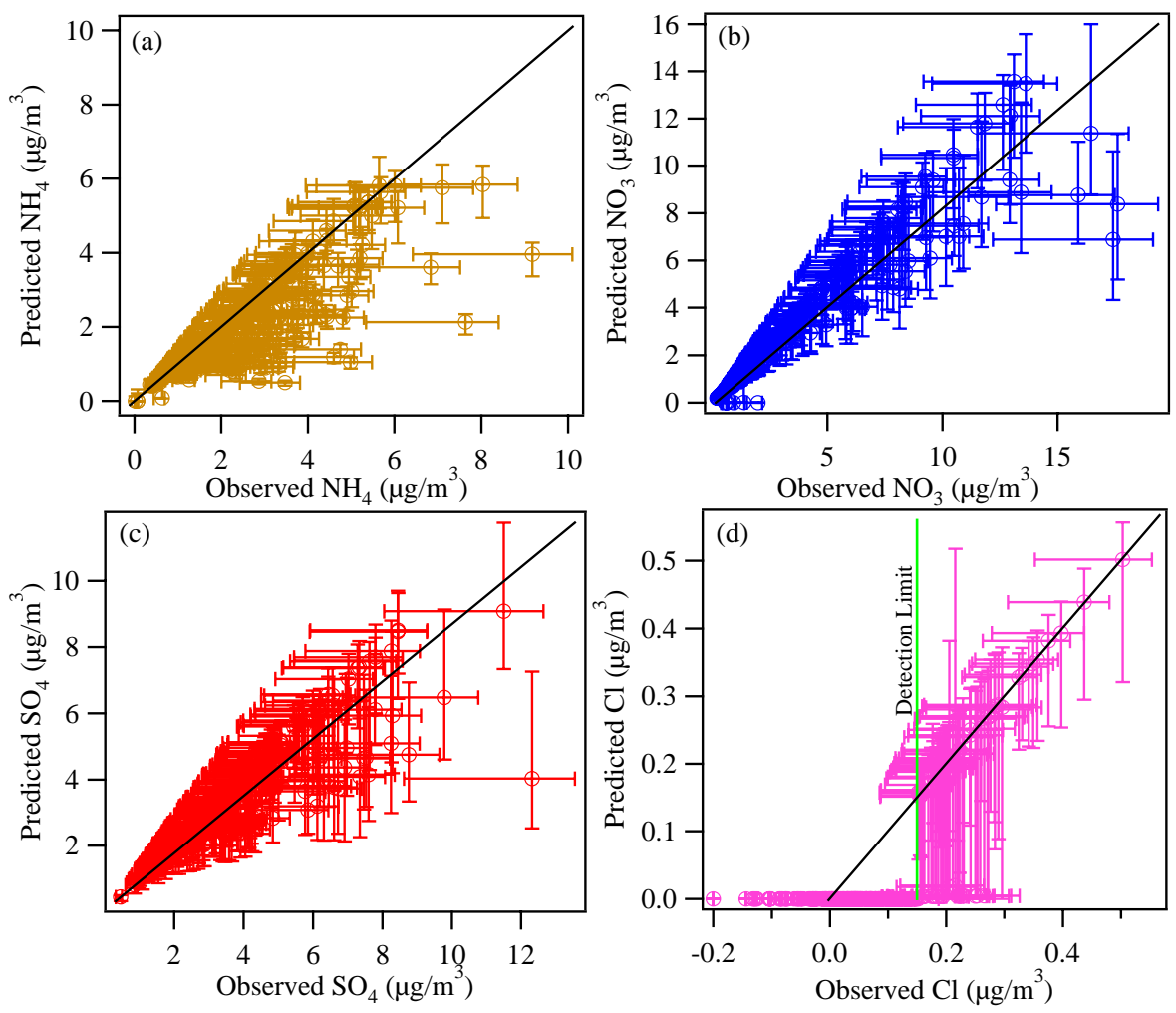

Fig. 10. Correlation plots for (a) ammonium, (b) nitrate, (c) sulphate, and (d) chloride for Pedregal. The error bars for the predictions represent the $95 \%$ confidence interval; the measurement uncertainty is $+10 \%,-30 \%$. The detection limit for chloride is $0.15 \mu \mathrm{g} / \mathrm{m}^{3}$.

production rate of nitric acid on 9 April, while the former indicates that this excess nitrate will partition to the particle phase since the production of particle-phase ammonium nitrate is determined in part by whether the partial pressure product of ammonia and nitric acid is above the equilibrium constant. Similarly, the production of particle-phase ammonium chloride is determined in part by whether the partial pressure product of ammonia and hydrochloric acid is above the equilibrium constant.

Finally, it is interesting to note that the predicted $\mathrm{pH}$ for the acidic period is comparable to the predicted $\mathrm{pH}$ at La Merced when the aerosols are assumed to be metastable; the most likely $\mathrm{pH}$ varies between 2.5 and 4.0 (see Part I). The average estimated $\mathrm{pH}$ was 3.7 on 9 April and 3.9 for the period where the particles are aqueous on 10-11 April.

\subsection{Pedregal}

Figures 10 and 11 compare the predicted and observed particle and gas phase species at the Pedregal site for the 2123 April measurement period. Of the 311 points that were analyzed, the mode of 301 of the posterior ammonia distributions was within the measurement uncertainty. Of the 10 points where the mode of the distribution was outside of the measurement uncertainty, the $95 \%$ confidence interval overlapped the measurement uncertainty in all but two cases.
Figure 10 confirms that, with the exception of 9 April at CENICA, the agreement between the observations and predictions of the particle phase species is generally within the measurement uncertainties. Specifically, in contrast to the predictions at CENICA on 9 April, 10:00 a.m. to 07:00 p.m. (CDT), the model does not systematically underpredict the nitrate observations. Both slight over- and underpredictions occur, with only very few predictions beyond the measurement uncertainties. Significant "negative chloride observations" underscore the uncertainties associated with the chloride observations and the rationale for the $0.15 \mu \mathrm{g} / \mathrm{cm}^{3} \mathrm{de}-$ tection limit (San Martini et al., 2006). Negative chloride concentrations were also reported at CENICA (minimum observation $=-0.43 \mu \mathrm{g} / \mathrm{m}^{3}$ ) and Santa Ana (minimum observation $=-0.13 \mu \mathrm{g} / \mathrm{m}^{3}$ ). The predictions of gas phase ammonia and nitric acid at Pedregal are consistent with those at CENICA and Santa Ana: excellent agreement between the ammonia predictions and observations, while the calculated $\mathrm{NO}_{\mathrm{z}}$ is both over- and underpredicted by the model.

Figure 12 shows the observed and predicted particle chloride and the predicted $\mathrm{HCl}(\mathrm{g})$ concentration at Pedregal. Figure 12 confirms the results at La Merced described in Part I (San Martini et al., 2006) and at CENICA on 10-11 April. Note that $\mathrm{HCl}(\mathrm{g})$ was only predicted if both the particle chloride was above the detection limit and the gas phase 

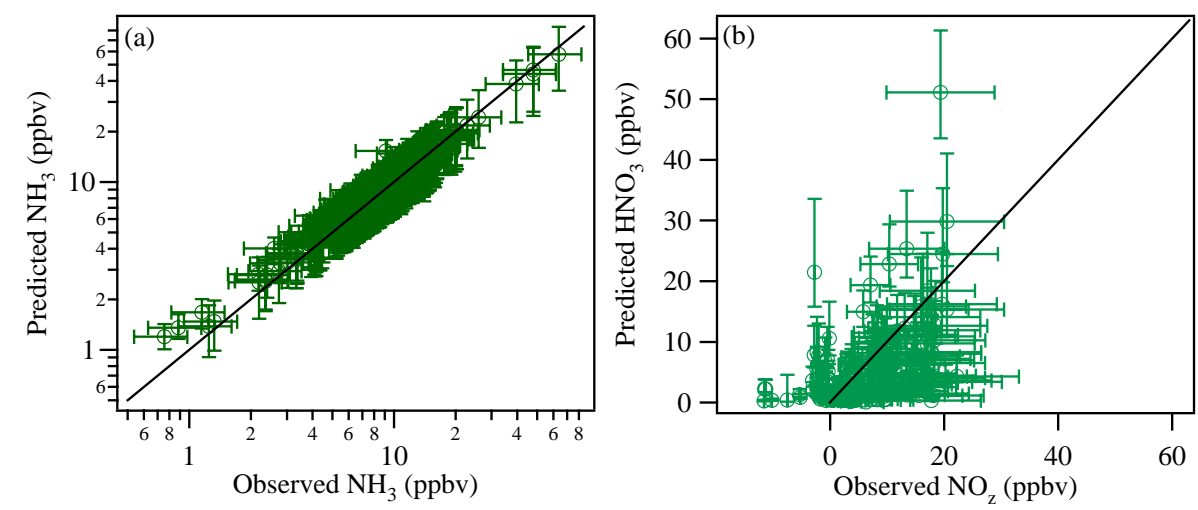

Fig. 11. Correlation plots for (a) ammonia and (b) $\mathrm{NO}_{\mathrm{z}}$ and nitric acid for Pedregal. The error bars for the predictions represent the $95 \%$ confidence interval; the measurement uncertainty for ammonia and $\mathrm{NO}_{\mathrm{Z}}$ is $\pm 29 \%$ and $\pm 49 \%$.

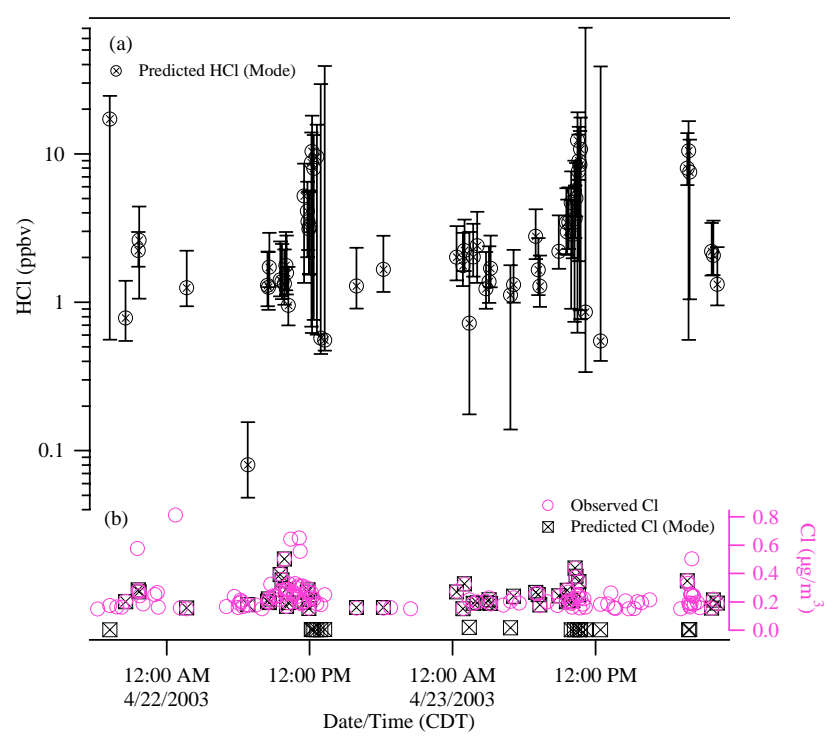

Fig. 12. (a) Posterior distribution of $\mathrm{HCl}$ (g) concentrations on 2223 April at Pedregal. The points represent the mode of the probability density function and the error bars are the $95 \%$ confidence intervals. Only points whose Markov Chain passed the convergence tests described in Part I are included. (b) Predicted (mode) and observed aerosol chloride concentrations, where only the observations above the detection limit are shown. The model was not run if the ammonia observations were lacking, even when the observed aerosol chloride concentration was above the detection limit.

ammonia observation was available. Thus, in general, chloride observations remained above the detection limit in the morning; during this period the predicted $\mathrm{HCl}$ (g) concentration was $\sim 1 \mathrm{ppbv}$ and increased to $\sim 10 \mathrm{ppbv}$ until around noon. After approximately noon, even if the observed particle chloride was above the detection limit, the chloride was predicted to remain in the gas phase even if $\mathrm{HCl}$ (g) concentrations in excess of $10 \mathrm{ppbv}$ were sampled by the Markov Chain. There are two exceptions to this finding: on 22 April
2003 at 15:56 and 18:12 the particle chloride are above the detection limit and the predicted $\mathrm{HCl}(\mathrm{g})$ concentration is $\sim 1-2$ ppbv.

\subsection{Santa Ana}

Figures 13 and 14 compare the predicted and observed particle and gas phase species at the Santa Ana site for the 14-16 April measurement period. Only a limited dataset is available since the model was only run when both particle and gas phase ammonia observations are available. The comparison of the predicted and observed particle concentrations at Santa Ana shown in Fig. 13 shows generally good agreement, with most predictions falling within the measurement uncertainties. The chloride predictions are particularly limited with only eight points above the detection limit when gas phase ammonia observations were available. Figure 14 shows excellent agreement between the ammonia predictions and observations, while the calculated $\mathrm{NO}_{\mathrm{z}}$ is mostly overpredicted by the model. Of the 152 points that were analyzed, the mode of 140 of the posterior ammonia distributions was within the measurement uncertainty. Of the 12 points where the mode of the distribution was outside of the measurement uncertainty, the $95 \%$ confidence interval overlapped the measurement uncertainty in all but four cases.

Figure 15 shows the observed and predicted particle chloride and the predicted $\mathrm{HCl}(\mathrm{g})$ concentration at Santa Ana. We emphasize that the predictions are limited to periods where both the ammonia observation is available and the observed particle chloride is above the detection limit. With this limitation in mind, for those points approximately before noon the $\mathrm{HCl}(\mathrm{g})$ concentration is predicted to be between $\sim 0.1$ and $\sim 1$ ppbv. In general, in other periods the chloride is predicted to partition to the gas phase despite the Markov Chain sampling high $\mathrm{HCl}$ (g) concentrations (up to $\sim 50 \mathrm{ppbv}$ ). An exception to this was found at approximately 15:20 on 16 April 2003, where appreciable chloride is predicted to partition to the particle phase. The predicted $\mathrm{HCl}$ 



Fig. 13. Correlation plots for (a) ammonium, (b) nitrate, (c) sulphate, and (d) chloride for Santa Ana. The error bars for the predictions represent the $95 \%$ confidence interval; the measurement uncertainty is $+10 \%,-30 \%$. The detection limit for chloride is $0.15 \mu \mathrm{g} / \mathrm{m}^{3}$.
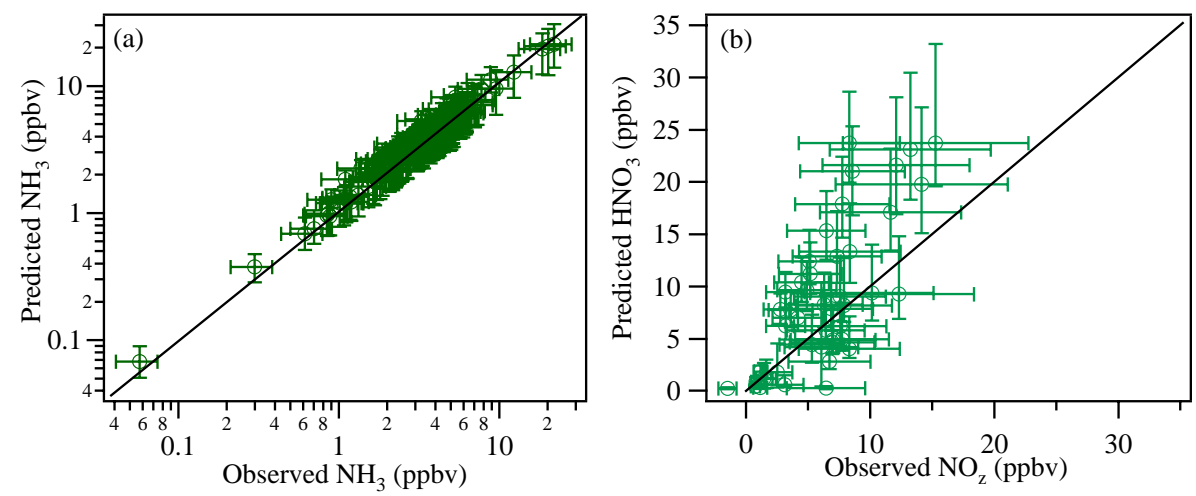

Fig. 14. Correlation plots for (a) ammonia and (b) $\mathrm{NO}_{\mathrm{z}}$ and nitric acid for Santa Ana. The error bars for the predictions represent the $95 \%$ confidence interval; the measurement uncertainty for ammonia and $\mathrm{NO}_{\mathrm{Z}}$ is $\pm 29 \%$ and $\pm 49 \%$.

(g) concentrations in this period are predicted to be $\sim 20$ 40 ppbv (see Fig. 15).

\section{Discussion}

ISORROPIA reproduces the particle observations well, with the exception of particle nitrate 10:00 a.m. to 07:00 p.m. on 9 April (see Fig. 5). As implemented here, the Markov Chain Monte Carlo method includes measurement but not model uncertainty.
A key model uncertainty is the effect of organic species on aerosol behavior. In spite of impressive advances in recent years, present understanding of organic aerosol composition, physical and chemical properties, sources and transformation characteristics is still limited (Fuzzi et al., 2006). Mixed organic-inorganic particles have been observed in a variety of ambient sampling studies (e.g., Duce et al., 1983; Hughes et al., 1999; Middlebrook et al., 1998; Noble and Prather, 1996; Rogge et al., 1993; Johnson et al., 2005). The water absorption of atmospheric aerosols has conventionally 


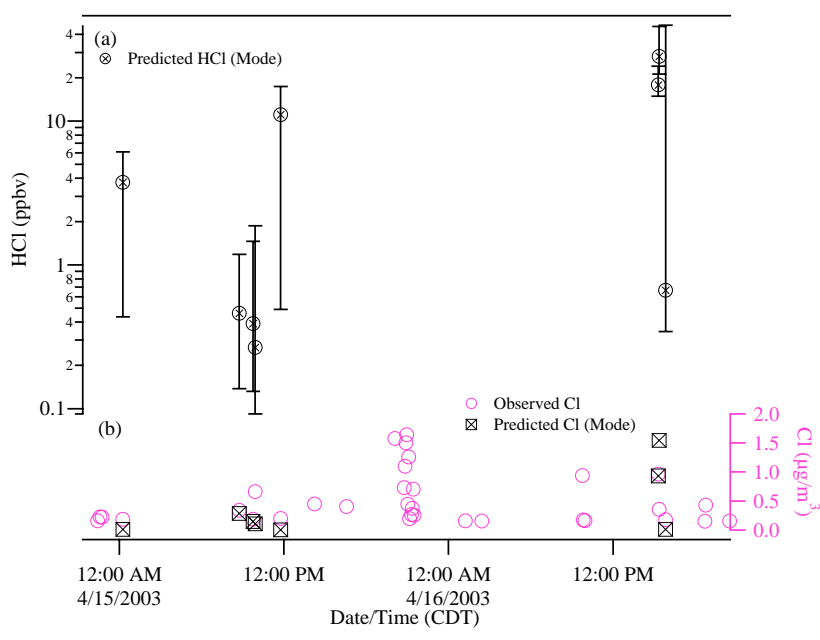

Fig. 15. (a) Posterior distribution of $\mathrm{HCl}$ (g) concentrations on 1516 April at Santa Ana. The points represent the mode of the probability density function and the error bars are the $95 \%$ confidence intervals. (b) Predicted (mode) and observed aerosol chloride concentrations, where only the observations above the detection limit are shown. Also excluded are chloride observations between $~ 20: 00$ and 21:00 on 15 April 2003. During this time very high concentrations of chloride were observed (up to $22 \mu \mathrm{g} / \mathrm{m}^{3}$ ). This plume, which was associated with very high organic aerosol concentrations, was traced to trash burning. No ammonia observations are available during this period. The model was not run if the ammonia observations were lacking, even when the observed aerosol chloride concentration was above the detection limit.

been associated with their inorganic fraction; theoretically and experimentally, little information exists about the hygroscopic behavior of particles containing organic compounds (Fuzzi et al., 2006). The aerosol model used in this work, ISORROPIA, only treats the inorganic aerosol species.

Studies of the effect of organics on the hygroscopicity of inorganic aerosols and the partitioning of inorganic species are, in general, limited and somewhat contradicting in the literature. Some researchers have suggested that organics have a negative effect on the growth factor or evaporation rate of inorganics (e.g., Lightstone et al., 2000; Marcolli and Krieger, 2005; Marcolli et al., 2004; Xiong et al., 1998), others a positive effect (e.g., Andrews and Larson, 1993; Ansari and Pandis, 2000; Varutbangkul et al., 2006), and others both a positive and negative effect (e.g., Choi and Chan, 2002; Cruz and Pandis, 2000; Saxena et al., 1995) or no effect (Hameri et al., 1997; 1998). Various researchers have implemented mixed organic-inorganic thermodynamic aerosol models (e.g., Clegg et al., 2003; Griffin et al., 2003; Koo et al., 2003; Ming and Russel, 2002; Pun et al., 2002; Saxena and Hildemann, 1997). While recent advances have greatly contributed to the field, only a small portion of the organic species found in the atmosphere have been investigated under relatively idealized conditions. Thus modeling secondary organic aerosol (SOA) formation and (primary + secondary) organic aerosol thermodynamics is very difficult due to major uncertainties in the gas-phase chemistry of organic aerosol formation, phase-partitioning of the condensable organic gases, and the molecular identity and thermodynamics of organic PM (McMurry, 2000; Zhang et al., 2000). Although some models and SOA observations (Marr et al., 2006) exist, recent results from Mexico City and other locations show that current models may underpredict SOA formation by close to an order of magnitude (Volkamer et al., 2006).

Given the uncertainties in the literature, it is interesting to note that the deviations in nitrate concentrations found in this work are consistent with the predictions of Ansari and Pandis (2000). These authors predicted that on average SOA accounts for approximately $7 \%$ of the total predicted aerosol water, and increases the predicted nitrate partitioning by approximately 10\% (Ansari and Pandis, 2000). The effect of SOA on aerosol water content decreased with increasing relative humidity. However, the mass fraction of SOA appeared to be more important in determining the magnitude of the effect, with increasing SOA mass fractions leading to increasing aerosol water content. Thus, despite being less hygroscopic than inorganic components, the SOA contribution can be as high as $15-20 \%$ for areas where the particle mass is dominated by SOA, as is the case in the MCMA. Specifically, based on the work of Ansari and Pandis (2000), the conditions on 9 April (high relative humidity and nitric acid production rates, combined with less efficient dilution and high SOA concentrations) indicate that SOA will likely have an appreciable effect on aerosol water content. This increased aerosol water content may help explain the nitrate underprediction observed in the afternoon of 9 April as the increased water content may increase nitrate partitioning to the particle phase (Ansari and Pandis, 2000). A limitation of the work of Ansari and Pandis is that organic compounds were assumed to not change the thermodynamics (i.e., activity coefficients) of the inorganic components.

Our results indicate that under certain conditions inorganic nitrate concentrations may be affected by SOA to a significant extent. Such feedbacks are not obvious from our data for other inorganic aerosol components. Further experimental data on water uptake of SOA and models that account for this additional water and nitric acid uptake, as well as the effect of SOA species on the activity coefficients, will be valuable in furthering our understanding of aerosol behavior.

In Part I we showed that the model is able to accurately reproduce the particle-phase chloride observations when the observations are consistently above the detection limit, and that during these periods the predicted $\mathrm{HCl}(\mathrm{g})$ concentrations are well constrained. This is confirmed in this work (see Figs. 7 and 8). Part I (SanMartini et al., 2006) discusses the model uncertainties and limitations, in particular with respect to the treatment of chloride species, and showed the predicted $\mathrm{HCl}$ concentration was dependent on whether the particles are stable or metastable. On 9 April at CENICA 
the most likely $\mathrm{HCl}$ concentration is predicted to remain in the sub-ppbv range throughout the day when the particles are assumed to remain aqueous; the average and maximum mode of the $\mathrm{HCl}$ posterior distribution is $1 \mathrm{ppbv}$ and $2.5 \mathrm{ppbv}$ when the particles are assumed to be dry between noon and 05:00 p.m. on 9 April. On 10-11 April the most likely $\mathrm{HCl}$ concentration is predicted to remain in the sub-ppbv range when the particles are aqueous. In the late morning of 11 April, the particles are predicted to be dry at equilibrium; in this case the most likely $\mathrm{HCl}$ concentration is predicted to be as high as $\sim 8$ ppbv.

The importance of chlorine on the photochemistry in the MCMA is unclear. Tanaka et al. found that chlorine may have a significant effect on the photochemistry of some urban environments (Tanaka et al., 2000, 2003), and the effect of salt chemistry on photochemistry in the vicinity of saline dry lakebeds has been previously noted (Hebestreit et al., 1999).

We note in particular that salt particles may be important to the photochemistry in the MCMA. Recall that the dry saltlake in the northeast of the city is a source of salt particles. In addition to the reaction of salt particles with nitric acid to produce $\mathrm{HCl}(\mathrm{g})$, reactions that may be important include (Finlayson-Pitts and Hemminger, 2000):

$$
\begin{aligned}
& \mathrm{N}_{2} \mathrm{O}_{5}+\mathrm{NaCl} \rightarrow \mathrm{NaNO}_{3}+\mathrm{ClNO}_{2} \\
& \mathrm{NO}_{3}+\mathrm{NaCl} \rightarrow \mathrm{NaNO}_{3}+\mathrm{Cl} \\
& \mathrm{ClONO}_{2}+\mathrm{NaCl} \rightarrow \mathrm{NaNO}_{3}+\mathrm{Cl}_{2} \\
& 2 \mathrm{NO}_{2}+\mathrm{NaCl} \rightarrow \mathrm{NaNO}_{3}+\mathrm{ClNO}
\end{aligned}
$$

$\mathrm{ClNO}_{2}, \mathrm{Cl}_{2}$, and $\mathrm{CINO}$ dissociate to highly reactive $\mathrm{Cl}$, which can then react with ozone (Finlayson-Pitts and Hemminger, 2000). Reactions (11-14) in Mexico City can lead to ozone formation, i.e. via Cl-radical initiated VOC oxidation (Reaction 16), or destruction, i.e. via Reaction (15) and the subsequent scavenging of $\mathrm{NO}_{\mathrm{x}}$ from the atmosphere:

$\mathrm{O}_{3}+\mathrm{Cl}^{\cdot} \rightarrow \mathrm{ClO}+\mathrm{O}_{2}$

However $\mathrm{Cl}^{\cdot}$ may also react with organics, e.g.,

$\mathrm{RH}+\mathrm{Cl}^{\cdot} \rightarrow \mathrm{HCl}+\mathrm{R}^{\cdot}$

where $\mathrm{RH}$ and $\mathrm{R}$ - are e.g. an alkane and alkane radical. The rate constants for Reactions (15) and (16) are $\mathrm{k}_{15}=10^{-11} \mathrm{~cm}^{3} /$ molecule $\mathrm{s}$ and $\mathrm{k}_{16}=10^{-10} \mathrm{~cm}^{3} /$ molecule $\mathrm{s}$. Reaction (16) may be particularly important to the photochemistry in the MCMA given the high concentrations of alkanes previously observed in the MCMA (Blake and Rowland, 1995). In fact most Cl-radicals will react with alkanes even in the presence of high ozone concentrations during afternoons.

The importance of $\mathrm{HCl}$ as a source of chlorine radicals, and hence on the photochemistry in the MCMA, can be approximated by considering Reactions (15), (16) and the daytime formation of $\mathrm{Cl}$ ( $\mathrm{HCl}$ does not photolyze in the troposphere):

$\mathrm{HCl}+\mathrm{OH}^{\cdot} \rightarrow \mathrm{H}_{2} \mathrm{O}+\mathrm{Cl}^{\cdot}$
The rate constant for Reaction (17) is $\mathrm{k}_{17}=10^{-12} \mathrm{~cm}^{3} /$ molecule's. Assuming the residence time of $\mathrm{Cl}^{-}$is determined by Reactions (15) and (16) only:

$\frac{1}{\tau_{C l} .} \sim k_{15}\left[\mathrm{O}_{3}\right]+k_{16}[\mathrm{RH}]$

The ratio of $\mathrm{Cl} / \mathrm{OH}$-radical concentrations is given by:

$\frac{[\mathrm{Cl} \cdot]}{[\mathrm{OH} \cdot]} \sim \frac{k_{17}[\mathrm{HCl}]}{k_{15}\left[\mathrm{O}_{3}\right]+k_{16}[\mathrm{RH}]}$

Representative concentrations in the MCMA of ozone and RH are $\sim 100$ ppbv $\left(3 \times 10^{12}\right.$ molecules $\left./ \mathrm{cm}^{3}\right)$ (Velasco et al., 2006). With $\mathrm{k}_{17}=10^{-12} \mathrm{~cm}^{3} /$ molecule $\mathrm{s}$, and assuming a concentration of $\mathrm{HCl}(\mathrm{g}) \sim 1 \mathrm{ppbv}\left(2 \times 10^{10}\right.$ molecules $\left./ \mathrm{cm}^{3}\right)$ yields a ratio of $\mathrm{Cl} / \mathrm{OH} \cdot$ of $\sim 6 \times 10^{-5}$.

The importance of $\mathrm{HCl}(\mathrm{g})$ as a source of chlorine radicals to the alkane photochemistry in the MCMA is determined by the relative importance of Reaction (16) to the reaction of $\mathrm{OH}$ with $\mathrm{RH}$ :

$\mathrm{RH}+\mathrm{OH}^{\cdot} \rightarrow \mathrm{H}_{2} \mathrm{O}+\mathrm{R}^{\cdot}$

The ratio of the reaction rate constant for Reaction (20) to Reaction (16) for propane, n-butane, and n-heptane is $\frac{1}{90}, \frac{1}{40}$, and $\frac{1}{14}$, respectively. Using n-butane as a representative example to estimate an upper limit effect on photochemistry (the single most abundant alkane in Mexico City actually is propane; Blake and Rowland, 1995), an $\mathrm{HCl}$ (g) concentration of $\sim 1$ ppbv yields a ratio of $\sim 400$, i.e., the percent contribution of $\mathrm{Cl}^{-}$radicals to $\mathrm{RH}$ oxidation is $\sim 0.2 \%$. Even concentrations of $\mathrm{HCl}(\mathrm{g})$ of $\sim 10 \mathrm{ppbv}$ yield only a $2 \%$ contribution of $\mathrm{Cl}^{-}$radicals to $\mathrm{RH}$ oxidation. The effect of $\mathrm{Cl}$. radicals from $\mathrm{HCl}$ to alkane photochemistry is thus expected to be very minor. The net effect of $\mathrm{HCl}(\mathrm{g})$ on ozone production may in fact be negative if scavenging of $\mathrm{NO}_{\mathrm{x}}$ into nitrated chlorine reservoirs, organic nitrates, and scavenging of $\mathrm{HO}_{\mathrm{x}}$ into $\mathrm{ClOH}$, as well as the subsequent possible removal from the gas-phase was considered.

It should be pointed out that the only source for $\mathrm{Cl} \cdot$ radicals considered here is our predicted most likely concentration of $\mathrm{HCl}(\mathrm{g})$. We have neglected other $\mathrm{Cl}$ - radical sources (e.g., photolysis of $\mathrm{Cl}_{2}, \mathrm{ClNO}_{2}, \mathrm{ClNO}$, etc.) in our analysis. Particularly $\mathrm{Cl}_{2}$ can jump-start photochemical ozone production in Houston (Tanaka et al., 2003). To our knowledge neither $\mathrm{Cl}_{2}$ nor $\mathrm{HCl}$ measurements have been reported in Mexico City to date. It is noteworthy that chlorinated hydrocarbons account for $1-2.5 \%{ }_{C}$ of total VOCs in Mexico City (Velasco et al., 2006). Our results indicate that $\mathrm{HCl}(\mathrm{g})$ is likely present in substantial concentrations. The upper limit values for $\mathrm{HCl}(\mathrm{g})$ predictions indicate that $\mathrm{Cl}$ radical release is at the verge of being relevant for photochemistry. The source of $\mathrm{HCl}(\mathrm{g})$ and other sources for $\mathrm{Cl} \cdot$ radicals are presently not clear, and further investigation of the importance of chlorine on the photochemistry in the MCMA is warranted. 


\section{Conclusions}

Using observations taken at three sites during the MCMA2003 campaign we showed that the model described in Part I (SanMartini et al., 2006) is, in general, able to accurately predict the observed inorganic particle concentrations. The agreement between the predicted and observed ammonia concentrations is excellent. The $\mathrm{NO}_{\mathrm{z}}$ calculated from the $\mathrm{NO}_{\mathrm{y}}, \mathrm{NO}$ and $\mathrm{NO}_{2}$ observations during this campaign is of limited use in constraining the nitric acid concentration given the large uncertainties in this measure of nitric acid.

Focusing on the acidic period of 9-11 April identified by Salcedo et al. (2006), the model accurately predicts the particle phase observations during this period with the exception of the nitrate predictions after approximately 10:00 a.m. (CDT) on 9 April, where the model underpredicts the observations. While the 9-11 April period was identified as acidic by Salcedo et al. (2006), ISORROPIA predicts comparable $\mathrm{pH}$ values during this and other periods where the particles are predicted to be aqueous. The predicted $\mathrm{pH}$ of the aqueous particles in the MCMA was $\sim 3-4 \mathrm{pH}$ units despite the high concentrations of gas phase ammonia observed.

For periods when the particle chloride observations are consistently above the detection limit, the model is able to accurately predict the particle chloride predictions and the predicted $\mathrm{HCl}(\mathrm{g})$ concentrations are well constrained. When the particles are aqueous, the most likely concentrations of $\mathrm{HCl}$ (g) are in the sub-ppbv range. The most likely predicted concentration of $\mathrm{HCl}(\mathrm{g})$ was found to reach concentrations of order $10 \mathrm{ppbv}$ when the particles are dry. While the Markov Chain Monte Carlo method used here provides a powerful tool to predict $\mathrm{HCl}$, direct observations of gas phase $\mathrm{HCl}$ in future campaigns will be invaluable. These observations will lead to a better understanding of aerosol behavior in the MCMA as well as the importance of chlorine chemistry to MCMA's photochemistry. Finally, future work will utilize the particle phase observations and predicted gas-phase probability distributions calculated here and in Part I to determine the effect of changes in precursor concentration on inorganic aerosol in the MCMA.

Acknowledgements. The financial support of the Comisión Ambiental Metropolitana of Mexico and of the U.S. National Science Foundation (Award ATM 308748 and ATM 0528227) and the Department of Energy for this work is gratefully acknowledged. Aerodyne would like to thank CAM, the National Science Foundation's Atmospheric Chemistry Program, and the Department of Energy's Atmospheric Sciences Program for financial support. D. Salcedo, K. Dzepina, and J. L. Jimenez would like to thank NSF (grant ATM-0528634) and DOE (grant DE-FG02-05ER63981) for funding. K. Dzepina is recipient of an Advanced Study Program fellowship from the National Center for Atmospheric Research. R. Volkamer acknowledges consecutive fellowships by Henry and Camille Dreyfus Foundation and Alexander von Humboldt Foundation. F. M. San Martini would like to thank B. de Foy for helpful discussions.
Edited by: U. Pöschl

\section{References}

Andrews, E. and Larson, S. M.: Effect of Surfactant Layers on the Size Changes of Aerosol-Particles as a Function of RelativeHumidity, Environ. Sci. Technol., 27(5), 857-865, 1993.

Ansari, A. S. and Pandis, S. N.: Water Absorption by Secondary Organic Aerosol and Its Effect on Inorganic Aerosol Behavior, Environ. Sci. Technol., 34(1), 71-77, 2000.

Blake, D. R. and Rowland, F. S.: Urban Leakage of Liquefied Petroleum Gas and Its Impact on Mexico City Air Quality, Science, 269(5226), 953-956, 1995.

Choi, M. Y. and Chan, C. K.: The effects of organic species on the hygroscopic behaviors of inorganic aerosols, Environ. Sci. Technol., 36(11), 2422-2428, 2002.

Clegg, S. L., Seinfeld, J. H., and Brimblecombe, P.: Thermodynamic Modelling of Aqueous Aerosols Containing Electrolytes and Dissolved Organic Compounds, Aerosol Sci., 32, 713-778, 2003.

Cruz, C. N. and Pandis, S. N.: Deliquescence and Hygroscopic Growth of Mixed Inorganic-Organic Atmospheric Aerosol, Environ. Sci. Technol., 34(20), 4313-4319, 2000.

de Foy, B., Caetano, E., Magaña, V., Zitácuaro, A., Cárdenas, B., Retama, A., Ramos, R., Molina, L. T., and Molina, M. J.: Mexico City basin wind circulation during the MCMA-2003 field campaign, Atmos. Chem. Phys., 5, 2267-2288, 2005, http://www.atmos-chem-phys.net/5/2267/2005/.

Duce, R. A., Pohnen, V. A., Zimmerman, P. R., Grosjean, D., Cautreels, W., Chatfield, R., Jaenicke, R., Ogren, J. A., Pellizzari, D., and Wallace, G. T.: Organic Material in the Global Troposphere, Rev. Geophys., 21, 921-952, 1983.

Finlayson-Pitts, B. J. and Hemminger, J. C.: Physical Chemistry of Airborne Sea Salt Particles and Their Components, J. Phys. Chem. A, 104, 11 463-11477, 2000.

Fuzzi, S., Andreae, M. O., Huebert, B. J., Kulmala, M., Bond, T. C., Boy, M., Doherty, S. J., Guenther, A., Kanakidou, M., Kawamura, K., Kerminen, V.-M., Lohman, U., Russel, L. M., and Poeschl, U.: Critical assessment of the current state of scientific knowledge, terminology, and research needs concerning the role of organic aerosols in the atmosphere, climate, and global change, Atmos. Chem. Phys., 6, 2017-2038, 2006, http://www.atmos-chem-phys.net/6/2017/2006/.

Griffin, R. J., Nguyen, K., Dabdub, D., and Seinfeld, J. H.: A Coupled Hydrophobic-Hydrophilic Model for Predicting Secondary Organic Aerosol Formation, J. Atmos. Chem., 44, 171190, 2003.

Hameri, K., Charlson, R. J., Hansson, H.-C., and Jacobson, M.: Hygroscopic properties of ammonium sulfate aerosols mixed with slightly soluble organic compound, J. Aerosol Sci., 28(Supplement 1), S153-S154, 1997.

Hämeri, K., Charlson, R. J., Hansson, H.-C., and Jacobson, M.: Hygroscopic properties of ammonium sulfate aerosol particles mixed with slightly soluble organic compound, J. Aerosol Sci., 29(Supplement 1), 587-588, 1998.

Hebestreit, K., Stutz, J., Rosen, D., Matveiv, V., Peleg, M., Luria, C., and Platt, U.: DOAS Measurements of Tropospheric Bromine Oxide in Mid-Latitudes, Science, 283, 55-57, 1999. 
Hughes, L. S., Allen, J. O., Kleeman, M. J., Johnson, R. J., Cass, G. R., Gross, D. S., Gard, E. E., Gaelli, M. E., Morrical, B. D., Fergenson, D. P., Dienes, T., Noble, C. A., Liu, D.-Y., Silva, P. J., and Prather, K. A.: Size and Composition Distribution of Atmospheric Particles in Southern California, Environ. Sci. Technol., 33(20), 3506-3515, 1999.

Johnson, K. S., Zuberi, B., Molina, L. T., Molina, M. J., Iedema, M. J., Cowin, J. P., Gaspar, D. J., Wang, C., and Laskin, A.: Processing of soot in an urban environment: case study from the Mexico City Metropolitan Area, Atmos. Chem. Phys., 5, 30333043, 2005,

http://www.atmos-chem-phys.net/5/3033/2005/.

Kolb, C. E., Herndon, S. C., McManus, B., Shorter, J. H., Zahniser, M. S., Nelson, D. D., Jayne, J. T., Canagaratna, M. R., and Worsnop, D. R.: Mobile laboratory with rapid response instruments for real-time measurements of urban and regional trace gas and particulate distributions and emission source characteristics, Environ. Sci. Technol., 38(21), 5694-5703, 2004.

Koo, B., Ansari, A. S., and Pandis, S. N.: Integrated Approaches to Modeling the Organic and Inorganic Atmospheric Aerosol Components, Atmos. Environ., 37, 4757-4768, 2003.

Lightstone, J. M., Onasch, T. B., Imre, D., and Oatis, S.: Deliquescence, efflorescence, and water activity in ammonium nitrate and mixed ammonium nitrate/succinic acid microparticles, J. Phys. Chem. A, 104(41), 9337-9346, 2000.

Marcolli, C. and Krieger, U. K.: The Deliquescence/Efflorescence Cycle of Organic/Ammonium Sulfate Particles: Phases, Phase Transitions, and Salt Effects, Geophys. Res. Abstr., 7, 03337, 2005.

Marcolli, C., Luo, B. P., and Peter, T.: Mixing of the organic aerosol fractions: Liquids as the thermodynamically stable phases, J. Phys. Chem. A, 108(12), 2216-2224, 2004.

Marr, L. C., Dzepina, K., Jimenez, J. L., Reisen, F., Bethel, H. L., Arey, J., Gaffney, J. S., Marley, N. A., Molina, L. T., and Molina, M. J.: Sources and transformations of particle-bound polycyclic aromatic hydrocarbons in Mexico City, Atmos. Chem. Phys., 6, 1733-1745, 2006, http://www.atmos-chem-phys.net/6/1733/2006/.

McMurry, P. H.: A Review of Atmospheric Aerosol Measurements, Atmos. Environ., 34, 1959-1999, 2000.

Middlebrook, A. M., Murphy, D. M., and Thomson, D. S.: Observations of Organic Material in Individual Marine Particles at Cape Grim during the First Aerosol Characterization Experiment (ACE 1), J. Geophys. Res., 103(D13), 16472-16483, 1998.

Ming, Y. and Russel, L. M.: Thermodynamic Equilibrium of Organic-Electrolyte Mixtures in Aerosol Particles, AIChE Journal, 48(6), 1331-1348, 2002.

Mozurkewich, M.: The Dissociation Constant of Ammonium Nitrate and its Dependence on Temperature, Relative Humidity and Particle Size, Atmos. Environ., 27A(2), 261-270, 1993.

Nenes, A., Pandis, S., and Pilinis, C.: ISORROPIA: A new thermodynamic equilibrium model for multiphase multicomponent inorganic aerosols, Aquatic Geochemistry, 4, 123-152, 1998.

Noble, C. A. and Prather, K. A.: Real-Time Measurement of Correlated Size and Composition Profiles of Individual Atmospheric Aerosol Particles, Environ. Sci. Technol., 30(9), 2667-2680, 1996.

Pun, B. K., Griffin, R. J., Seigneur, C., and Seinfeld, J. H.: Secondary Organic Aerosol 2: Thermodynamic Model for
Gas/Particle Partitioning of Molecular Constituents, J. Geophys. Res., 107(D17), 4333, doi:2001D000542, 2002.

Rogge, W. F., Mazurek, M. A., Hildemann, L. M., Cass, G. R., and Simoneit, B. R. T.: Quantification of Urban Organic Aerosols at a Molecular-Level-Identification, Abundance, and SeasonalVariation, Atmos. Environ., 27A, 1309-1330, 1993.

Rood, M. J., Shaw, M. A., Larson, T. V., and Covert, D. S.: Ubiquitous Nature of Ambient Metastable Aerosol, Nature, 337(9), 537-539, 1989.

Salcedo, D., Onasch, T. B., Dzepina, K., Canagaratna, M. R., Zhang, Q., Huffman, J. A., De Carlo, P. F., Jayne, J. T., Mortimer, P., Worsnop, D. R., Kolb, C. E., Johnson, K. J., Zuberi, B., Marr, L. C., Volkamer, R., Molina, L. T., Molina, M. J., Cardenas, B., Bernabé, R. M., Marquez, C., Gaffney, J. S., Marley, N. A., Laskin, A., Shutthanadan, V., Xie, Y., Brune, W. H., Lesher, R., Shirley, T. R., and Jiminez, J. L.: Characterization of Ambient Aerosols in Mexico City during the MCMA-2003 Campaign with Aerosol Mass Spectrometry: results from the CENICA Supersite, Atmos. Chem. Phys., 6, 925-946, 2006,

http://www.atmos-chem-phys.net/6/925/2006/.

San Martini, F. M., West, J. J., Sosa, G., Molina, L. T., Molina, M. J., and McRae, G. J.: Modeling Inorganic Aerosols and their Response to Changes in Precursor Concentration in Mexico City, J. Air Waste Manage. Assoc., 55(6), 803-815, 2005.

San Martini, F. M., Dunlea, E. J., Grutter, M., Onasch, T. B., Jayne, J. T., Canagaratna, M. R., Worsnop, D. R., Kolb, C. E., Shorter, J. H., Herndon, S. C., Zahniser, M. S., Ortega, J. M., McRae, G. J., Molina, L. T., and Molina, M. J.: Implementation of a Markov Chain Monte Carlo method to inorganic aerosol modeling of observations from the MCMA-2003 campaign - Part I: Model description and application to the La Merced site, Atmos. Chem. Phys., 6, 4867-4888, 2006,

http://www.atmos-chem-phys.net/6/4867/2006/.

Saxena, P. and Hildemann, L. M.: Water Absorption by Organics: Survey of Laboratory Evidence and Evaluation of UNIFAC for Estimating Water Activity, Environ. Sci. Technol., 31(11), 33183324, 1997.

Saxena, P., Hildemann, L. M., McMurry, P. H., and Seinfeld, J. H.: Organics Alter Hygroscopic Behavior of Atmospheric Particles, J. Geophys. Res.-Atmos., 100(D9), 18 755-18 770, 1995.

Shirley, T. R., Brune, W. H., Ren, X., Mao, J., Lesher, R., Cardenas, B., Volkamer, R., Molina, L. T., Molina, M. J., Lamb, B., Velasco, E., Jobson, T., and Alexander, M.: Atmospheric oxidation in the Mexico City Metropolitan Area (MCMA) during April 2003, Atmos. Chem. Phys., 6, 2753-2765, 2006, http://www.atmos-chem-phys.net/6/2753/2006/.

Tanaka, P. L., Oldfield, S., Mullins, C. B., and Allen, D. T.: Anthropogenic Sources of Chlorine in Urban Atmospheres, Environ. Sci. Technol., 34, 4470-4473, 2000.

Tanaka, P. L., Riemer, D. D., Chang, S., Yarwood, G., McDonaldBuller, E. C., Apel, E. C., Orlando, J. J., Silva, P. J., Jimenez, J. L., Canagaratna, M. R., Neece, J. D., Mullins, C. B., and Allen, D. T.: Direct Evidence of Chlorine-Enhanced Urban Ozone Formation in Houston, TX, Atmos. Environ., 37, 1393-1400, doi:10.1016/S1352-2310(02)01007-5, 2003.

Varutbangkul, V., Brechtel, F. J., Bahreini, R., Ng, N. L., Keywood, M. D., Kroll, J. H., Flagan, R. C., Seinfeld, J. H., Lee, A., and Goldstein, A. H.: Hygroscopicity of secondary organic aerosol formed by oxidation of cycloalkenes, monoterpenes, sesquiter- 
penes, and related compounds, Atmos. Chem. Phys., 6, 23672388, 2006,

http://www.atmos-chem-phys.net/6/2367/2006/.

Velasco, E., Lamb, B., Westberg, H., Allwine, E., Sosa, G., Arriaga, J. L., Jonson, T., Alexander, M., Prazeller, P., Knighton, W. B., Rogers, T. M., Grutter, M., Herndon, S. C., Kolb, C. E., Zavala, M. A., Volkamer, R. M., de Foy, B., Molina, L. T., and Molina, M. J.: Distribution, magnitudes, reactivities, ratios and diurnal patterns of volatile organic compounds in the Valley of Mexico during the MCMA 2002 and 2003 field campaigns, Atmos. Chem. Phys. Discuss., 6, 7563-7621, 2006, http://www.atmos-chem-phys-discuss.net/6/7563/2006/.

Volkamer, R., Jimenez, J. L., San Martini, F. M., Dzepina, K., Zhang, Q., Salcedo, D., Molina, L. T., Worsnop, D. R., and Molina, M. J.: Secondary Organic Aerosol Formation from Anthropogenic Air Pollution: Rapid and Higher than Expected, Geophys. Res. Lett., 33, L17811, doi:10.1029/2006GL026899, 2006.
Volkamer, R., Molina, L. T., Molina, M. J., Shirley, T. R., and Brune, W. H.: DOAS measurement of glyoxal as an indicator of fast VOC chemistry in urban air, Geophys. Res. Lett., 32, L08806 doi:10.1029/2005GL022616, 2005.

Xiong, J. Q., Zhong, M. H., Fang, C. P., Chen, L. C., and Lippmann, M.: Influence of organic films on the hygroscopicity of ultrafine sulfuric acid aerosol, Environ. Sci. Technol., 32(22), 3536-3541, 1998.

Zhang, Y., Seigneur, C., Seinfeld, J. H., Jacobson, M., Clegg, S. L., and Binkowski, F. S.: A comparative review of inorganic aerosol thermodynamic equilibrium modules: similarities, differences, and their likely causes, Atmos. Environ., 34, 117-137, 2000. 